\title{
Insights into biogeochemical cycling and unanticipated geobiological trajectory after alum addition to an engineered lake
}

\author{
G.L. JeSSEN ${ }^{1,2}$ L-X. CheN ${ }^{3}$, J. F. Mori ${ }^{2,4}$, T. C. Nelson ${ }^{2,5}$, \\ F.G. SLATER ${ }^{5}$, S. B. RUdDERHAM ${ }^{6}$, M. B. J. LINDSAY ${ }^{6}$, J. F. \\ BANFIELD ${ }^{3}$ AND L.A. WARREN ${ }^{2,5}$ \\ 1 Institute de Ciencias Marinas y Limnológicas, Universidad Austral de Chile \\ 2 Department of Civil and Mineral Engineering, University of Toronto \\ 3 Earth and Planetary Science, University of California Berkeley \\ 4 Graduate School of Nanobioscience, Yokohama City University \\ 5 School of Geography and Earth Sciences, McMaster University \\ 6 Department of Geological Sciences, University of Saskatchewan, Saskatoon, SK, Canada
}

Assessment of reclamation strategies involving water capped tailings technology (WCTT), provides a unique opportunity to evaluate the developmental interplay between microbial communities and interlinked $\mathrm{C}, \mathrm{N}$ and $\mathrm{S}$ cycling as redox biogeochemical niches are established. Here we investigate the interactions between geochemistry, microbial community structure and function at Base Mine Lake (BML), the first commercial scale demonstration pit lake (WCTT) in Canada. Water cap and fluid fine tailings (FFT) results (2016-2018), combining 16S rRNA gene amplicons (Archaea and Bacteria) sequencing, shotgun metagenomics, and geochemistry, identify dynamic and interactive microbial and biogeochemical development. This three-year sampling period started with a whole basin alum $\left(\mathrm{AlSO}_{4}{ }^{2-}\right)$ treatment, to increase light penetration, promote photosynthetic productivity and support an oxic layer within the water cap. After this intervention, an increasing trend of severe hypoxic to anoxic bottom waters during late summer stratification occurred in both subsequent years. This result is complemented by a shift towards anaerobic heterotrophic metabolisms, consistent with the encoding genes detected through metagenome results, as well as an observed greater depletion of thermodynamically favorable electron acceptors such as oxygen and nitrate. Further, the emergent combination of an water cap anoxic region with high relative sulfate concentrations pose a risk to oxygen levels through newly enabled water cap sulfate reduction and subsequent re-oxidation of generated sulfide.

These whole lake alum amendment time series results provide new insights into the establishment and development of ecological and geobiochemical trajectories which may be imperceptible in more natural contexts; and help guide the development of biologically informed strategies for better mine wastewater management and reclamation. 